\title{
Research on Intelligent Marketing Mode of Power under the Background of Big Data
}

\author{
Shunchao Wang ${ }^{1, a^{*}}$,Songxue Hou ${ }^{1, b}$, Hong Shen $^{1, c}$, Yan Liu ${ }^{1, d}$ \\ and Xiaochun Zhang ${ }^{1, \mathrm{e}}$ \\ ${ }^{1}$ Technical training center of Hubei electric power company, China \\ aW_shunchao@163.com, b909030532@qq.com, '895383918@qq.com, \\ d512088453@qq.com, e97691960@qq.com \\ *The corresponding author
}

\section{Keyword: Big Data; Power Enterprise; Intelligent Marketing}

\begin{abstract}
This paper first defines the concept of the power big data and intelligent marketing, and then describes the status of power marketing in developed countries such as the United States, Japan and Britain, and then analyzes the pressure the traditional marketing mode of traditional power of China is facing at current stage, and based on this, proposes constructing new intelligent marketing mode of power under the background of big data. Which means taking big data platform as data support, it forms continuous closed loop mode by "power marketing data collection----data analysis----mode construction----intelligent evaluation", and finally gives specific strategies for implementation of intelligent marketing mode of power.
\end{abstract}

\section{Introduction}

Power industry is an important foundation of China's national economy, while power marketing is the key to the development and operation of power enterprises. The traditional power marketing, due to restrictions from all aspects, is limited to the infrastructure work such as settlement of electricity charges, cost reminder and home maintenance and so on. It is difficult for the traditional marketing mode of power to meet the actual needs of the production and operation of power companies at current stage.

With the rapid development of information technology, the power energy companies have possessed big data resources. The big data brings new challenges as well as new opportunities to production and operation of the power company. The power big data optimizes production and operation of power energy companies, which can effectively promote China' s power energy companies to transform from the extensive development mode of high energy consumption, low efficiency and high emissions to green development mode of low energy consumption, high efficiency and low emissions. The establishment of a new type of electric power production and marketing mode by integrating the internal subsystem data of power energy company and integrating it into the power big data platform, can not only fully solve problems of low power fault repair efficiency, high electricity recovery pressure, poor economic benefits of grid operation etc at the present stage, but also more effectively meet the urgent needs of power customers for premium power and efficient services.

With dual background of the trend of big data era and internal demand for lean and high-quality power enterprise management, the exploration and practice of intelligent marketing mode of power under background of big data is imminent. Therefore, this article will give a deep research on intelligent marketing mode of power by taking advantages of big data, so as to solve the existing problems of the traditional marketing mode, and meet the customers' demands for security, real-time, environmental energy.

All manuscripts must be in English, also the table and figure texts, otherwise we cannot publish your paper.

Please keep a second copy of your manuscript in your office. When receiving the paper, we assume that the corresponding authors grant us the copyright to use the paper for the book or journal in question. 
Should authors use tables or figures from other Publications, they must ask the corresponding publishers to grant them the right to publish this material in their paper.

Use italic for emphasizing a word or phrase. Do not use boldface typing or capital letters except for section headings (cf. remarks on section headings, below).

\section{Current Research Situation of Foreign Power Marketing}

The Connotation of Power Big Data. The power big data is a necessary process of technological change of the electric power industry. The power big data not only represents the technology progress, but also involves significant changes of development concept, management system and technical route etc of the entire power system under the background of big data. Two main lines of power big data are to reshape the core value of power and transform mode of power development.

Through mining the benign development of power energy companies and meeting the individual demand of the market, the power big data drives the power enterprises to re-examine their own core values from "people-oriented" height, and to transform from "centering on electric power production" to "centering on customers" needs". The mining of data value, can provide a series of effective solutions to the construction of each link of generation, transportation, distribution, transmission and use of power in power industries, power marketing business development, enhancement of auxiliary decision-making ability of power information system. The technology of power big data includes: data mining, data visualization, statistical analysis and Hadoop distributed computing technology, etc.

The Connotation of Intelligent Marketing. Taking the realization of control of power market panorama as the goal, the intelligent marketing timely responses to macro and micro fluctuation factor of power market and has strong visibility and controllability, which can gradually realize the demand and involve in response, and reflect the linkage characteristic of supply and demand integration, and finally can supply users with various channels to involve in power market and means to control of macro energy market.

Through the use of digital technology, the intelligent marketing mode associates power grid operation with business needs, social benefits, etc. The intelligent marketing mode, through the comprehensive automation of management, sales and marketing system, realizes the real time interaction and the balance of energy supply and demand between power grid enterprises and market participants. Intelligent marketing mode is a more secure, more economical, more environmentally friendly power services and selling mode.

Research Status of Power Marketing in Developed Countries. The change of grid architecture of developed countries is small, and the development of power market is mature and tends to be steady, the demand tends to be saturated, the power supply and excess reserves tend to be balanced, and maximization of market benefits and minimization of blackout time is the focus of attention.

The power grid in North America, primarily in the US, starts early and develops more maturely. Marketing security and reliability of power supply is the focus of the research on the marketing mode in the North American power grid. The power supply companies in North American have introduced power price policies such as discount of customers' combined electric meters, charging preferential of traffic tools, price discount of peak averting and shifting at seasonal and time interval, so as to cope with electricity waste and avoid peak power demand, etc.

The power marketing business of Japan mainly includes: contract affairs, remote meter reading, electricity price and rate calculation, increase of supply and expansion of sales, etc. The characteristics of power marketing mode of Japan are mainly as follows: in the catalog price, set differential power prices to guide peak load flow and reduce cost of the power supply; apply to the ministry of economy for record, make special charges directory such as implementing preferential policies to all electric residence and increase the sale of electricity; actively promote new energy storage air conditioning to users, etc.

Britain has mature links of generation, transportation, distribution, transmission and use of power and powerful trading settlement system, its power marketing work mainly includes installing and connecting of power, charge query reservation, loading and reading of meter, fault handling, power-off notification and restoration of power supply and power quality. The characteristic of power marketing 
mode is that it allows the users to freely choose the sales price plan, and also allows flexible and diverse payment time scale and settlement.

Compared to China, power marketing of developed countries has more serviceability and integration, and technical work which is closely combined with marketing is in various technical departments. With respect to the marketing mode and organization structure, power marketing department of foreign power enterprises is less, and all of their work centers on customer. The main work is to provide customers with consultation and design scheme related to demands for electric energy, and technical work such as reading meter, charging electric fees and urgent repair are outsourced to the third party companies.

\section{Pressures the Traditional Marketing Mode of Power Is Facing}

With the deepening reform of China's electricity market, the current operation mode of electric power enterprises is developing to direction of the power market demand and improvement of customers' satisfaction. The new situation puts forward higher requirements to the power marketing, and brings pressures in many ways to operation of power enterprises.

First, demand for customers' service is growing. At present, residents and enterprises are increasingly dependent on electricity, while less tolerant of blackout. Especially during unplanned period or fault blackout, high-quality service is facing increasing pressure, which puts forward higher requirements for quality services of the power enterprise.

Second, the lean management of electric power enterprise puts forward higher requirements on the line loss management. The line loss management, as one of the three major economic indicators to assess the management level of electric power enterprises, is an important link of enterprises to reduce loss, conserve energy and improve efficiency. Problems such as weak maneuverability in system construction, insufficient technology dynamic management of line loss management, unreasonable design of grid, low accuracy of customers' meter measurement, but the key core problem is distortion of line loss statistics index.

Third, the recovery situation of electric fees is severe.

\section{Intelligent Marketing Mode Design of Power in Big Data Era}

The big data environment provides the possibility of obtaining, analyzing, processing and utilizing the information of consumers, markets and products needed by intelligent marketing of power. Intelligent marketing mode of power, takes big data platform as data support, and forms continuous closed loop mode consisting of "power marketing data collection, data analysis, mode construction, intelligent evaluation” (As shown in Fig. 1).

Data collection. With big data platform, through portal sites, mobile terminals and other channels, tocollect system data of power marketing business, including: supply and sale data of electricity of each user, contract management data of power supply, newly installed, increased capacity and change of power consumption data, meter reading and billing data, the electric charge collection and accounting management data, power information collection data, electricity inspection management data, management data of measuring point, line loss and energy efficiency management data, management data of orderly power consumption, business processing data, 95598 customers' service data, data of management of customers' relationship, contact, and archive data management, data of inspection and work quality. At the same time, store the original data, process and analyze the real-time data and the existing data, and form the basic database. 


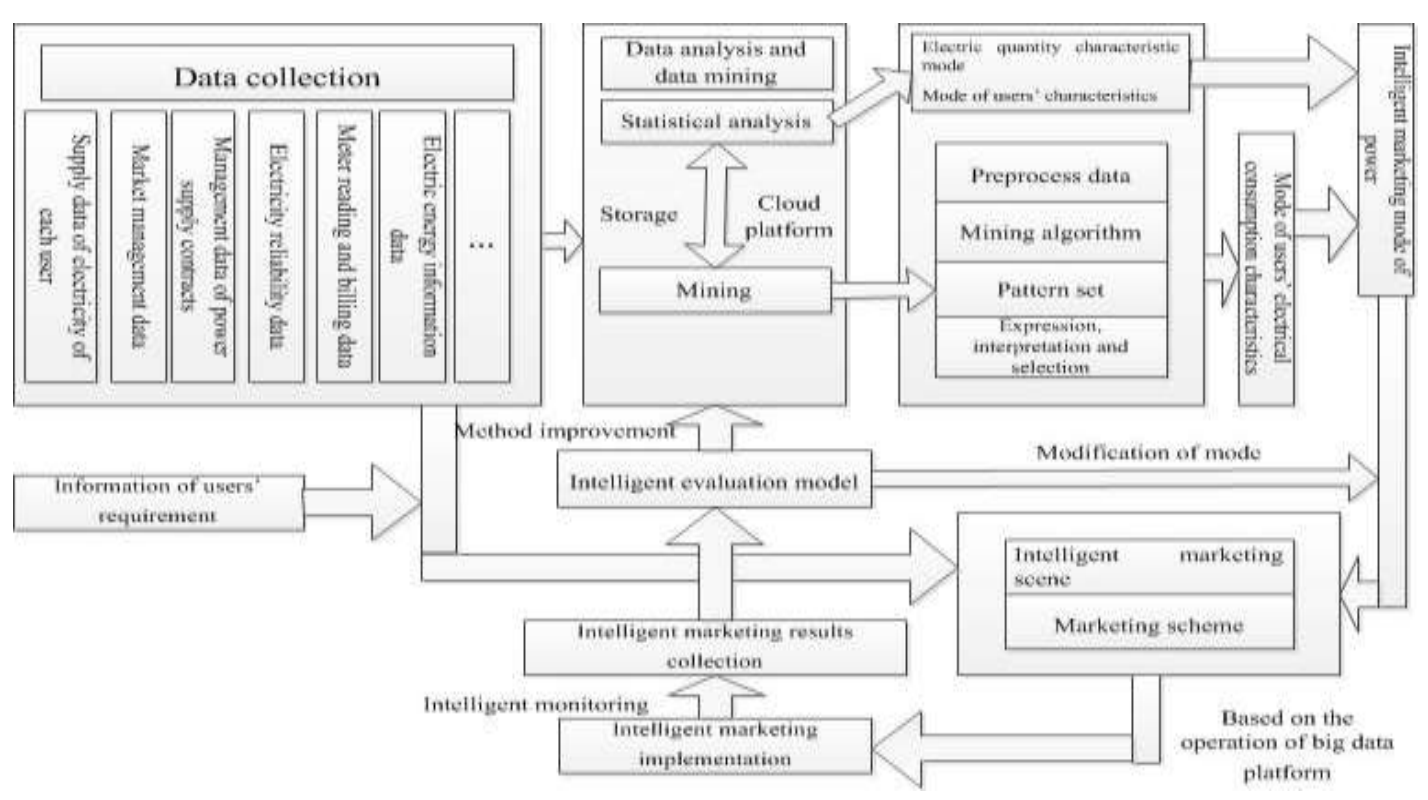

Figure 1. Intelligent marketing mode of electric power in big data environment

Data analysis. According to the basic database and real-time data of big data platform, further mine and analyze data, and by combination of all types of data including the national policy, the situation of social economic development, natural environment and other factors, do in-depth research on the law of electricity and the use of electricity in different regions and by different industries.

Mode construction. According to the characteristics and preferences of users, construct the mode of users' electrical consumption characteristics and intelligent marketing of power. Relying on big data platform, build intelligent marketing business scenarios, develop marketing program by combing with the marketing situation, so as to achieve mutual matching between content library and marketing programs. Through effective forecasting of electricity demand, design reasonably and accurately the side management of demand for consumption and orderly use of electricity, so as to improve the utilization of power resources; classify customers and implement targeted marketing and service strategy according to different customers; establish customer's credit rating model, and take effective measures to improve the level of electric charge recovery and avoid new electricity production into electricity; forecast abnormal using of electricity, to prevent stealing of electricity.

Smart assessment. Real-time update of the database enables timely mastery of power marketing information. With big data platform for real-time monitoring of marketing implementation process, provide online visual warning of the market abnormal data and state. Monitor the marketing situation on-line, deal with the sudden situation of marketing, produce decision-making scheme, give feedback of assessment information of the late market, revise the decision scheme, and provide scientific decision-making basis for the improvement of marketing mode at the next stage.

\section{Implementation Strategy of Intelligent Marketing Mode of Power}

Electric Energy Product Strategy. Product is one of the important factors of enterprise marketing, and ensuring the quality of electric energy products is the foundation and key of intelligent marketing of power. The cost difference of power supply enterprise needed for power supply reliability of different users. According to the principle of matching of cost and revenue in the market, classify different users, and collect differential price. Make a rapid distinction of huge meters of users by taking use of big data technology, collect differential price from all kinds of electric power users, so as to achieve the goal of fine management.

Dynamic Pricing Strategy. Big data environment makes online bidding possible. When the distributed power supply generates enough power to satisfy requirements of grid-connection, it then will issue power-sold intention to power marketing network platform. After receiving request for sale of 
power, the platform gives feedback to distributed power supply, inquires about expected on-grid electricity quantity, time and price, and releases in real-time the power-sold intention to network marketing platform of power. When the user agrees to on-grid use at the price, the platform, through advanced technology equipment of power grid, automatically complete online auction process of the distributed power supply. The platform can change the past pricing mechanism of "one factory, one price" for on-grid power generation, forms free competition of power generation in the market and makes the distributed power and power plants have the same market position, and taking use of economic leverage in market, reduce on-grid price, avoid peak reasonably, use energy effectively, so as to achieve the purpose of protecting the environment.

Strategy of High Quality Power Supply Service. According to stock and increment of the users' electricity consumption, the price level, electricity recovery rate, load rate, power level of the location, the energy consumption level, subdivide power sale market, using big data method to cluster users, find high-quality client group, take initiative to provide high-quality power supply service.

Electric Power Promotion Strategy. The first strategy is using electricity advertising for promotion. In advertising, focus on highlighting the clean energy property of power, and guide the public to fully understand and perceive economic, convenient, superior properties of electric energy products, and gradually form a cumulative publicity effect.

The second is correctly guiding the power customers to carry out power replacement work, by increasing the consumption proportion of electricity terminal, gradually promotes the power customers to change the concept of energy consumption.

\section{Summary}

Traditional power marketing mode is facing unprecedented opportunities and challenges in the era of big data. In the big data environment, the electric power company must keep pace with the times, through the construction of continuous closed loop mode consisting of "power marketing data collection, data analysis, mode construction, intelligent evaluation" , fully meets transformation demand of the power company under the background of big data in all aspects of production and operation, solves the problems existing in the traditional electric power marketing mode, and fully realizes power users' goal for security, real-time and environmental protection.

\section{References}

[1] EPRI. Power Delivery System and Electricity Markets of the Future[R]. Palo Alto, CA: EPRI, 2003.

[2] Tang Yuezhong, Shao Zhiqi, Guo Chuangxin, etc. Digital Power Grid Architecture [J]. Power Automation Equipment, 2009, 29 (6): 115-118.

[3] Zhao Qiuke. Research on Marketing Strategy of Power Supply Enterprise Leaf Science and Technology Outlook, 2014 (08).

[4] Nie Yunsheng, He Xuemin, Overview of Grid Power Marketing Mode of France, Japan and the United States, [J] State Grid, 2007 (8): 41

[5] Pang Jianjun. Analysis of the Development Trend of Power Marketing Industry in the Background of Big Data [J] Science and Technology Vision, 2014 (32): 295-296.

[6] Li Guojie. Scientific Value of Big Data Research [J]. Communications of the China Computer Federation, 2012.8 (9) -15.

[7] Xu Weiting, Hu Can, etc. An Overview of Intelligent Marketing Research: The Current Situation and Enlightenment of Foreign Research [J]. Electric Power Automation Equipment, 2010.2:72-74.

[8] National Power Grid Corp "Big Marketing" System Construction Implementation Plan [R]. National Power Grid Marketing Department, 2012.

[9] Zhuang Subing. The Power Supply Enterprise Marketing Management Mode Based on PDM the North China Electric Power University [D]. North China Electric Power University, 2006. 